\title{
Laser-induced, Surface Plasmon-enhanced Two-photon Excitation for Efficient Chemical Functionalization of Nanostructured Gold Surfaces
}

\author{
Kitjanit Neranon, ${ }^{\mathrm{a}}$ Mattias Åslund, ${ }^{\mathrm{b}}$ Max Yan, ${ }^{\mathrm{c}} \mathrm{Hao} \mathrm{Xu},{ }^{\mathrm{d}}$ Ying Fu, ${ }^{\mathrm{e}}$ Ingemar Petermann, ${ }^{\mathrm{f}}$ \\ Per Björk, ${ }^{\mathrm{f}}$ and Olof Ramström*a,g,h
}

\begin{abstract}
${ }^{a}$ Department of Chemistry, KTH - Royal Institute of Technology, Teknikringen 30, S-10044 Stockholm, Sweden; ${ }^{b}$ BiaTect AB, Sigurdvägen 30, 18254 Djursholm, Sweden; 'Department of Applied Physics, KTH - Royal Institute of Technology, Hannes Alfvéns Väg 12, 11419 Stockholm, Sweden; ${ }^{d}$ Department of Protein Science, KTH - Royal Institute of Technology, Stockholm, Sweden; ' School of Information Technology, Halmstad University, SE-301 18 Halmstad, Sweden; ${ }^{R}$ ISE Research Institutes of Sweden AB, Division Digital Systems, Box 1070, 16425 Kista, Sweden; ${ }^{g}$ Department of Chemistry, University of Massachusetts Lowell, One University Ave., Lowell, MA 01854, USA; Email: olof ramstrom@uml.edu; ${ }^{h}$ Department of Chemistry and Biomedical Sciences, Linnaeus University, SE-39182 Kalmar, Sweden
\end{abstract}

\begin{abstract}
Functionalized gold nanostructures with efficient, broadband absorption properties are of interest for a variety of biomedical applications. In this study, we report a plasmon-enhanced functionalization methodology that results in selective surface conjugation of a fluorescent probe via two-photon excitation under visible-wavelength laser irradiation. The fluorescent probe was designed to incorporate a thiolated 4-piperidinyl-1,8-naphthalimide (SNaph) entity, carrying a photolabile 6-nitroveratryl (NV) protecting group, straightforwardly synthesized in a few steps in good yield. Efficient plasmon-enhanced photodeprotection of the NV-group, followed by thiol-gold bond formation on gold nanoisland substrates was recorded upon exposure to $650 \mathrm{~nm}$ laser light, supported by confocal laser scanning microscopy (CLSM). Photolysis of the labile NV-group, thereby efficiently exposing the free mercapto group of the thiolated 1,8-naphthalimide, was recorded upon UV-irradiation at $350 \mathrm{~nm}$, whereas no cleavage occurred at $650 \mathrm{~nm}$. No conjugation occurred on featureless, gold-plated flat substrates under the same conditions. Surface plasmon-enhanced two-photon excitation at plasmonic hotspots in the absorber layer thus resulted in selective and efficient conjugation of the fluorescent probe to the structured surfaces. The resulting laser-assisted approach introduces the advantage of accomplishing selective molecular functionalization at plasmonic hotspots, owing to the combined, simultaneous effects of long-wavelength deprotection and spontaneous conjugation.
\end{abstract}

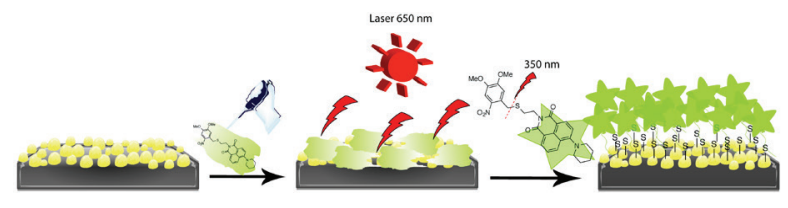

\section{INTRODUCTION}

Developments in the fields of nanoscience and nanotechnology have resulted in the emergence of a wide range of different nanostructures with unique chemical and physical properties. ${ }^{[1-12]}$ Of particular interest in this context is the interaction between nanomaterials and light. Light offers a large number of advantages when applied to nanomaterials: it is straightforward to apply and can be remotely controlled both spatially and temporally; it is relatively harmless to living organisms at longer wavelengths; and it is easily implemented on various platforms, providing an efficient means to exert external stimuli. ${ }^{[13-21]}$ 
Combined with the fact that certain nanostructures enable control of the absorption and diffraction resonances caused by surface plasmons upon incident light excitation, a wide range of applications can be perceived. Recent advances in the fabrication of plasmonic nanomaterials have also overcome major technical challenges and resulted in the enhanced understanding and use of surface plasmons in different applications. ${ }^{[22-27]}$ Engineered nanostructures thus have the ability to control surface plasmon generation, manipulation and transfer, resulting in light manipulation at the nanoscale. ${ }^{[28-32]}$ For example, distinctive extinction of the spectral bands within the visible and near infrared regions can result in highly effective absorption and emission. ${ }^{[16,18,33]}$ In particular, surface plasmons in the near infrared wavelength range play important roles in biological applications due to higher penetration of the skin, various tissues, and blood, accessible by light with a peak transmission at about $800 \mathrm{~nm} \cdot{ }^{[34]}$ As a result of this development, the area of plasmonic nanostructures and nanodevices have witnessed rapid expansion and afforded a range of applications in diagnosis, imaging, therapy, communication, quantum optics, photovoltaics, catalysis, lithography, and, in particular, for chemical- and bio-sensors. ${ }^{[35-44]}$ These advances have also addressed challenges concerning the diffraction limit in conventional applications.

For (bio)sensor applications, surface plasmon-enhanced two-photon excitation and associated luminescence is particularly attractive. This can result in sensitive detection, in part owing to the high signal-to-noise ratio obtained from the effective repression of the background noise. The features also enable enhanced 3D-imaging ability, and furthermore leads to minimal photodamage of organic chromophores. ${ }^{[46-50]}$ In organic molecules, twophoton excitation generally ranges from the red to near-infrared region with emission wavelengths in the blue to green visible range. ${ }^{[51,52]}$ Combined with the notion that two-photon excitation at near-infrared wavelengths are generally compatible with aqueous systems, and result in minimal absorption of biological chromophores, materials that enable two-photon excitation show high potential for biomedical applications. In contrast, photobleaching effects are often resulting from excitation with light at shorter wavelengths. ${ }^{[50,52]}$

Nanostructures based on noble metals possess many characteristics that make them suitable for these applications, ${ }^{[53-55]}$ and have attracted considerable interest as plasmonic nanomaterials. These structures often show broadband optical absorption, which ranges from visible to near-infrared wavelengths, in combination with high chemical and physical stability. ${ }^{[34]}$ The structures can be fabricated to present different sizes and shapes, and can furthermore be functionalized with a broad variety of organic molecules. Due to its high versatility and tunability, gold has proven especially suitable for the fabrication of functionalized plasmonic nanostructures, leading to an extensive exploitation in a wide range of applications, ${ }^{[33,34,52-56]}$ in particular for optical sensing and imaging systems. Controllable optical properties can also be achieved with composite nanostructures thereby enabling extraordinary properties in comparison to single nanoparticles. ${ }^{[33]}$ The possibility of achieving plasmonic hotspots between neighboring nanostructures is especially attractive, thereby enabling two-photon excitation at specific loci. Recently, we developed a composite, plasmonic nanostructure presenting a gold nanoisland top layer, showing efficient absorptivity throughout the visible wavelength range as well as a major portion of the near-infrared region. ${ }^{[57]}$ It could be shown that the absorption efficiency depended on dipole-based resonances, resulting in the ability to amplify optical phenomena at the top surface.

Taking the benefits of light, the chemistry of photolabile entities, and the attractive features of surface plasmons for light manipulation at the nanoscale, highly efficient and selective conjugation can be achieved. This has been demonstrated in the present study, where surface plasmon-enhanced two-photon excitation at gold nanoisland films has been used to 
selectively conjugate fluorescent molecular probes at plasmonic hotspots. This resulted in laser-induced, long-wavelength cleavage of photolabile protecting groups, thus exposing reactive thiol groups that enabled spontaneous bond formation on the gold surfaces. With this strategy, fluorophore-functionalized surfaces could be produced, showing the potential of generating ultrasensitive devices for bionanosensing and imaging.

\section{RESULTS AND DISCUSSION}

\section{Design and synthesis of fluorescent probe}

The probe structure was designed to be composed of three parts: a fluorescent entity for detection, a thioalkyl chain for attachment to the gold surface, and a photolabile thiol protecting group. The 4-amino-1,8-naphthalimide motif was chosen as the fluorophore owing to its attractive chemical and photophysical properties. ${ }^{[58,59]}$ This structure gives rise to internal charge transfer (ICT), with an absorption band centered around 380-450 nm, and an emission band at ca. 480-550 nm, depending on the solvent. It can furthermore be relatively easily modified through the imide- and 4-amino-groups and adapted to different applications. In the present case, a 4-piperidinyl 1,8-naphthalimide derivative was adopted for the probe entity, showing an absorption maximum at ca. $410 \mathrm{~nm}$ with a $\log \varepsilon$ value of $10^{4}$ in nonpolar media. ${ }^{[60,61]}$ The naphthalimide fluorophore unit was linked via an ethylene linker to the sulfur atom, which was suitably protected by the photolabile entity. A variety of light-sensitive protecting groups have for these reasons been developed, ${ }^{[62,63]}$ of which the 6-nitroveratryl (NV) structure was chosen for the present setup (Figure 1). This structure is compatible with sulfur chemistry and displays an absorption maximum around $350 \mathrm{~nm},{ }^{[64]}$ at which wavelength a molar extinction of $5 \times 10^{3} \mathrm{M}^{-1} \mathrm{~cm}^{-1}$, and a quantum yield of $\sim 0.07$ has been recorded. ${ }^{[65]}$ Irradiation at around $700 \mathrm{~nm}$ would thus be appropriate for the deprotection process to occur only at the plasmonic hotspots. The synthetic protocol of the targeted 6-nitroveratryl-protected fluorescent naphthalimide probe (NV-SNaph) is shown in Figure 1, following a straightforward three-step sequence that resulted in a relatively high overall yield. 6-Nitroveratryl bromide $\mathbf{1}$ was first efficiently converted to compound $\mathbf{2}$ in excellent yield via nucleophilic substitution by cysteamine in the presence of $\mathrm{LiOH}$ in $\mathrm{H}_{2} \mathrm{O} / \mathrm{EtOH} .{ }^{[66]}$ Subsequently, compound $\mathbf{2}$ was condensed with 4-bromo-1,8-naphthalic anhydride $\mathbf{3}$ to afford compound 4. Finally, nucleophilic aromatic substitution of the bromine atom at the 6-position of compound 4 in neat piperidine under refluxing conditions afforded the desired probe molecule NV-SNaph in moderate yield. ${ }^{[67]}$ 

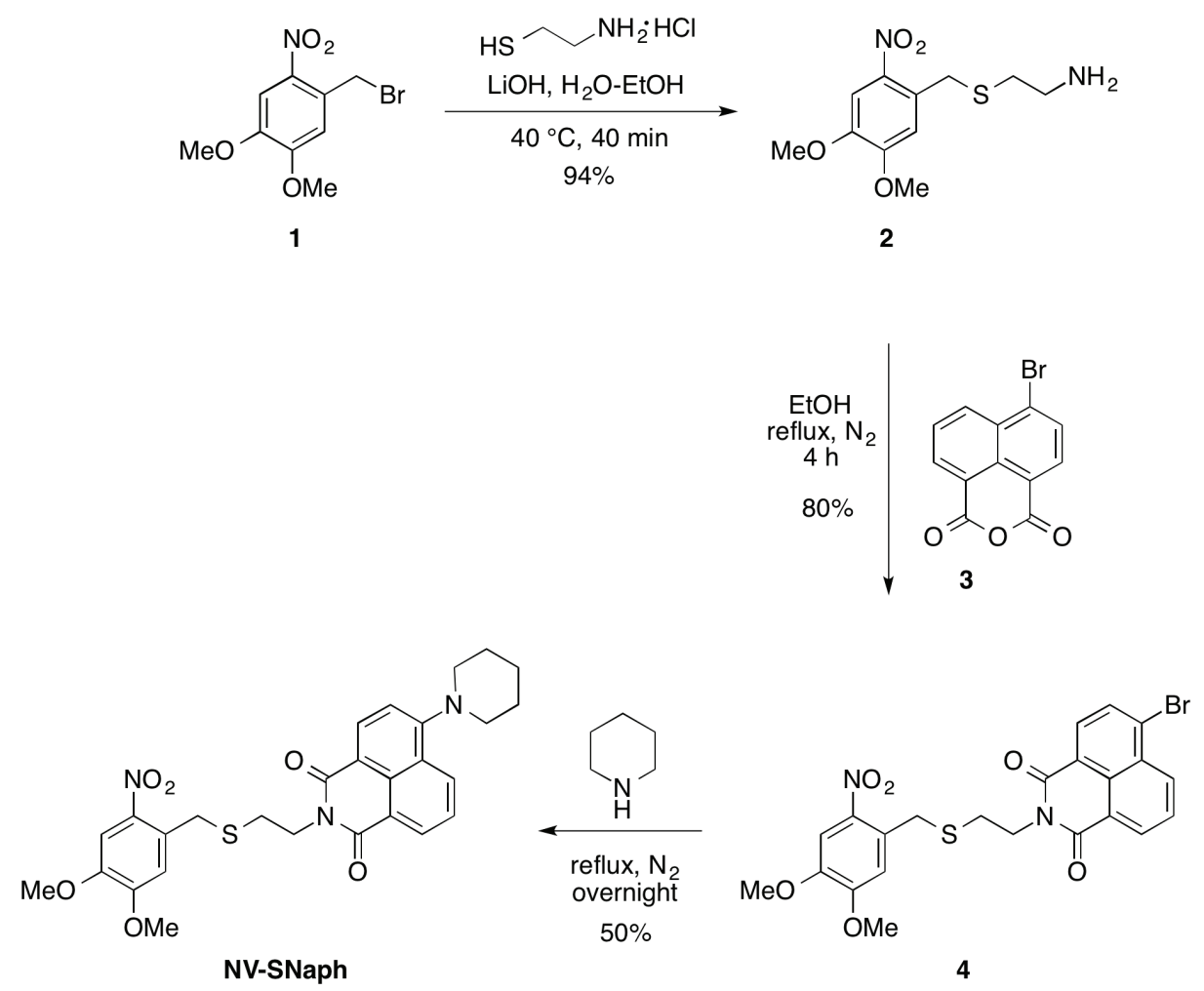

Figure 1: Synthesis of 6-nitroveratryl-protected 4-piperidinyl-1,8-naphthalimide fluorescent probe (NV-SNaph).

\section{Optical properties of NV-SNaph}

The spectroscopic properties, with respect to UV-Vis absorption and fluorescence, of the NVSNaph probe were next evaluated, primarily assessed in chloroform solution with concentrations of ca. $10^{-5} \mathrm{M}$ and $10^{-7} \mathrm{M}$, respectively. The $S$-protected cysteamine compound 2 was used as control, being devoid of the fluorescent naphthalimide group. As shown in Figure $\underline{2}$ (red line), compound $\mathbf{2}$ exhibited a maximum absorption band at around $350 \mathrm{~nm}$, thus showing characteristic optical properties of the 6-nitroveratryl group. ${ }^{[63,68]}$ Likewise, the UV-Vis absorption spectrum of the NV-SNaph probe (Figure 2 , black line), showed a distinct maximum absorption of the naphthalimide moiety at $411 \mathrm{~nm}$, in accordance with data reported for similar structures. ${ }^{[60,61]}$ The fluorescence emission spectrum of the NVSNaph probe $\left(\lambda_{\mathrm{ex}}=411 \mathrm{~nm}\right)$ is furthermore shown in Figure $\underline{2}$ (inset), with a maximum $\lambda_{\mathrm{em}}$ at $513 \mathrm{~nm}$ together with very high emission intensity at the low concentration used. These results indicated the potential of the NV-SNaph structure to function as a fluorescent probe in this study. Upon UV-irradiation of the NV-SNaph probe at $350 \mathrm{~nm}$, using a photochemical reactor at an intensity of $2 \mathrm{~mW} / \mathrm{cm}^{2}$, an increase in absorbance was observed at around $325-350 \mathrm{~nm}$ along with a decrease at $411 \mathrm{~nm}$ (Figure 2, blue line). This indicates photolysis of the 6-nitroveratryl group accompanied by release of the unprotected SNaph moiety. 


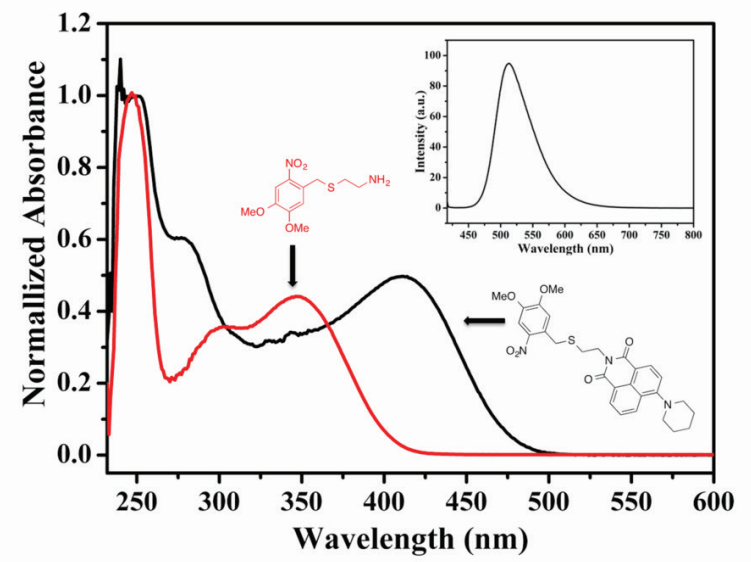

Figure 2: UV-Vis spectra of NV-SNaph (black line) compared with NV-protected thiol linkage 2 (red line). Inset: fluorescence spectrum of $\mathbf{N V}-\mathbf{S N a p h}\left(\lambda_{e x}=411 \mathrm{~nm}\right)$.

\section{Photolysis of the NV-SNaph probe studied by ${ }^{1} \mathrm{H}-\mathrm{NMR}$ - and UV-Vis-spectroscopy}

As mentioned, the 6-nitroveratryl group, comprising two methoxy groups on the benzene ring, displays a maximum absorption around $350 \mathrm{~nm}$ and can therefore be removed with relatively long-wavelength UV light compared to other protecting groups. ${ }^{[62,64]}$ The kinetics of the 6-nitroveratryl cleavage from the NV-SNaph probe under the influence of UV-light with a specific wavelength of $350 \mathrm{~nm}$ and an intensity of $1.8-2.0 \mathrm{~mW} / \mathrm{cm}^{2}$ was subsequently investigated. The ${ }^{1} \mathrm{H}-\mathrm{NMR}$ spectra obtained from the resulting photolysis during $60 \mathrm{~min}$ at room temperature in deuterated chloroform solution are shown in Figure $\underline{3}$. As can be seen, the signal around $\delta \approx 4.19 \mathrm{ppm}$, arising from the benzylic protons of the NV-SNaph probe decreased gradually, confirming successful photolysis.

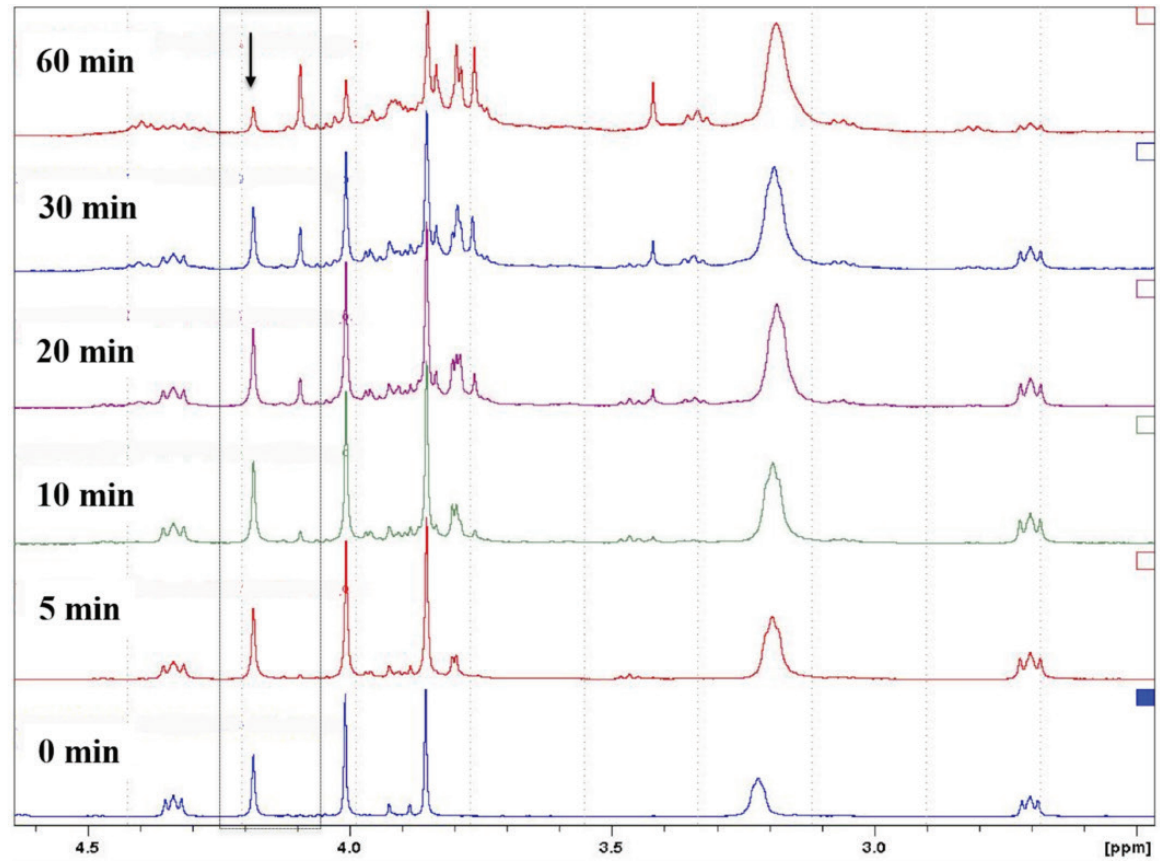

Figure 3: ${ }^{1} \mathrm{H}-\mathrm{NMR}$ spectra of $\mathbf{N V}-\mathbf{S N a p h}$ in $\mathrm{CDCl}_{3}$ before and after irradiation in UV photoreactor $(350 \mathrm{~nm}$, $I=1.8-2.0 \mathrm{~mW} / \mathrm{cm}^{2}$ ) for 0-60 $\mathrm{min}$.

In addition, the kinetics of the photodeprotection of the NV-SNaph probe was evaluated 
using UV-Vis spectroscopy to further confirm the structural change upon photolysis. In analogy to the ${ }^{1} \mathrm{H}$ NMR-study, the process was followed in chloroform solution $\left(10^{-5} \mathrm{M}\right)$ under exposure at $350 \mathrm{~nm}$ in a photochemical reactor for 1 hour (Figure 4). As shown in the above, the probe displayed an absorption band centered at $411 \mathrm{~nm}$, characteristic of the naphthalimide moiety, as well as a band at around 300-360 nm arising from the 6-nitroveratryl moiety. Upon UV-irradiation, a slow decrease in absorption was observed at $411 \mathrm{~nm}$, while the absorption at 300-360 nm gradually increased, along with a noticed color change of the solution from bright lime green to pale greenish yellow (Figure $\underline{4}$, inset). These results indicate that UV-light triggered the cleavage of the benzylic carbon-sulfur bond and provided the free $N$-thioethyl-4-piperidinyl-1,8-naphthalimide probe molecule. Thus, both ${ }^{1} \mathrm{H}-\mathrm{NMR}$ and UV-Vis-spectroscopy supported cleavage of the photolabile protecting 6-nitroveratryl group of the NV-SNaph probe under exposure to UV-light $(350 \mathrm{~nm})$, generating the free thiol entity linked to the fluorescent naphthalimide label.

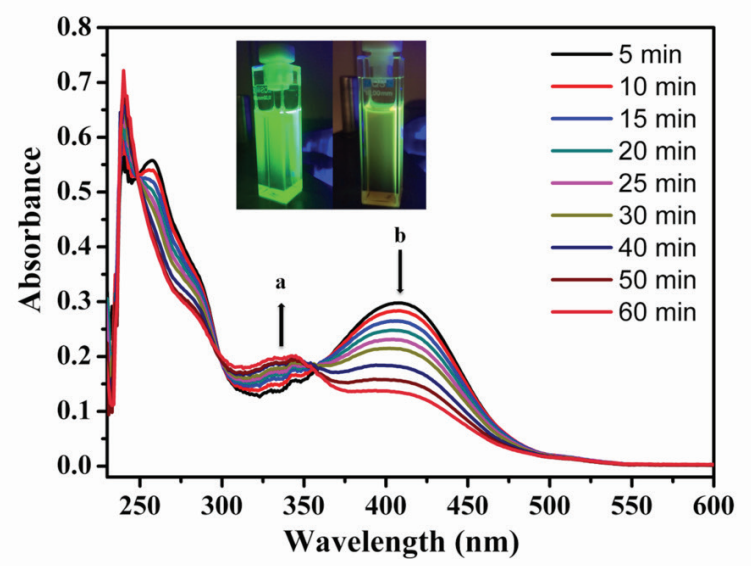

Figure 4: UV-Vis spectra of photolysis of $\mathbf{N V - S N a p h ~}\left(10^{-5} \mathrm{M}\right)$ in $\mathrm{CHCl}_{3}$ under irradiation in photoreactor (350 $\left.\mathrm{nm}, I=2.8-3.2 \mathrm{~mW} / \mathrm{cm}^{2}\right)$ for 0-60 min. Inset: fluorescence color change of $\mathbf{N V} \mathbf{S N a p h}(1.7 \mathrm{mg} / \mathrm{mL})$ before (left) and after (right) $350 \mathrm{~nm}$ UV-irradiation for $30 \mathrm{~min}$.

\section{Gold surface functionalization through UV-triggered cleavage of the NV-SNaph probe}

Having evaluated the photolysis of the 6-nitroveratryl moiety of the NV-SNaph probe in solution, the light-induced functionalization of flat, featureless gold surfaces was investigated (cf. supporting information). It was expected that deprotection and conjugation would occur at $350 \mathrm{~nm}$, whereas the 6-nitroveratryl group would be stable at the double wavelength. To visualize the chemical conjugation of the fluorescent probe onto the substrates resulting from photolysis of the carbon-sulfur bond of the NV-SNaph probe, confocal laser scanning microscopy (CLSM) was applied and the fluorescence images evaluated. Three different conditions were thus assessed: no irradiation, irradiation at $350 \mathrm{~nm}$, and irradiation at $650 \mathrm{~nm}$, respectively. The confocal images of the surfaces not having been exposed to any irradiation showed strong residual fluorescence at both the quartz- and gold-areas of the crystal before washing (Figure $\underline{5} \mathbf{a}$ ), however easily removed upon washing by dichloromethane (soaking overnight) to remove the physisorbed and/or excess amount of probes (Figure $\underline{5} \mathbf{b}$ ). The same results were obtained from crystals irradiated by laser light at $650 \mathrm{~nm}$, with no fluorescence detected after washing/soaking in dichloromethane (Figure $\underline{5} \mathbf{c}$ ). However, as expected, strong, residual, green fluorescence of the $N$-thioethyl-4-piperidinyl-1,8-naphthalimide probe was observed on the gold surfaces following irradiation at $350 \mathrm{~nm}$ and washing/soaking overnight (Figure $\underline{5} \mathbf{d}-\mathbf{e}$ ), whereas largely no fluorescence was observed on the quartz areas of 
the crystals. These results imply that the protected fluorescent probe could be deprotected by irradiation at $350 \mathrm{~nm}$, and subsequently chemisorbed on the gold surfaces via thiol-Au bond formation. Any physisorbed fluorophores could be easily removed by washing, after which only trace amounts were observed.
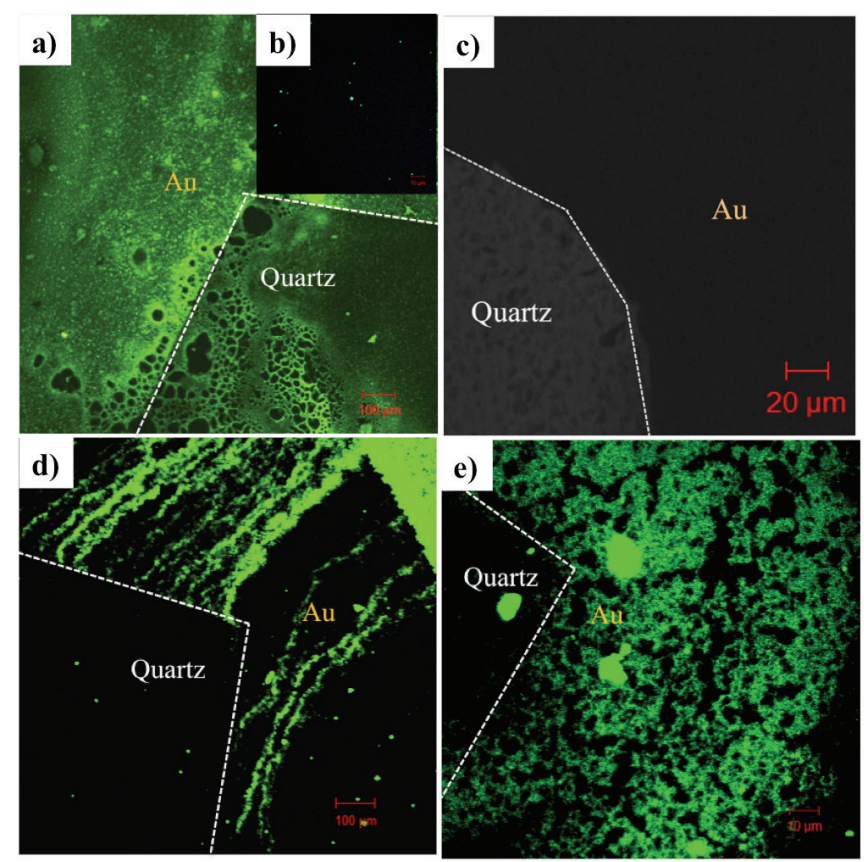

Figure 5: CLSM images of gold-plated quartz crystal substrates treated with the NV-SNaph probe. a) without irradiation before washing (10X); b) idem after washing (63X); c) irradiation by $650 \mathrm{~nm}$ laser for $30 \mathrm{~min}$ and washing (40X); d) irradiation at $350 \mathrm{~nm}$ for $30 \mathrm{~min}$ and washing (10X); e) idem (63X).

The hypothesis of using gold nanoisland surfaces to achieve two-photon excitation and chemical conjugation at plasmonic hotspots was next tested. The gold-nanoisland substrates were thus exposed to concentrated solutions of the NV-SNaph probe and further evaluated using the CLSM technique. The results were in this case very clear, and irradiation at either 650 or $350 \mathrm{~nm}$ resulted in strong, residual fluorescence, which could not be removed by washing (Figure $6 \mathbf{b}-\mathbf{c}$ ). This indicates efficient cleavage of the 6-nitroveratryl group followed by covalent ligation of the fluorescent naphthalimide probe onto the gold-nanoisland surfaces. In addition, a higher and more uniform coverage of the naphthalimide fluorophore was obtained upon laser irradiation at $650 \mathrm{~nm}$ (Figure $6 \mathbf{c}-\mathbf{d}$ ), compared to the results from irradiation at $350 \mathrm{~nm}$ (Figure $\underline{6} \mathbf{b}$ ). In contrast, only trace residual fluorescence could be observed at non-irradiated substrates used as a control after washing/soaking in dichloromethane overnight (Figure $\underline{6} \mathbf{a}$ ). This supports photolysis of the NV-SNaph probe, assisted by plasmon-enhanced two-photon excitation for ultimate gold-surface functionalization. Comparison of the results obtained from both types of gold substrates indicates that featured gold-nanoisland surfaces are required to result in conjugation at higher wavelengths. Although the 6-nitroveratryl protecting group cannot be directly cleaved using irradiation by laser light at $650 \mathrm{~nm}$, where the wavelength is outside the excitation band, the gold-nanoisland surfaces can produce a plasmonic effect resulting in energy at half the wavelength $(\lambda / 2)$ of the source (around $325 \mathrm{~nm}$ ). Thereby, the photolabile protecting group can be removed, and the thioethyl-derivatized naphthalimide fluorophore become attached to the gold surfaces. 

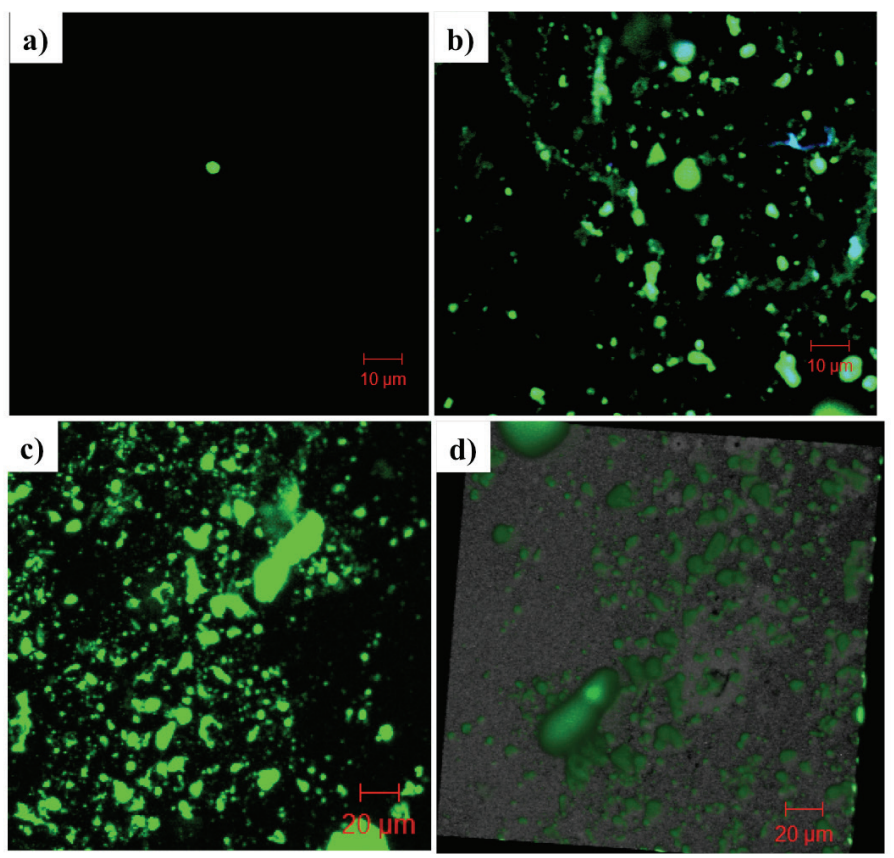

Figure 6: CLSM images of gold nanoisland substrates treated with the NV-SNaph probe. a) no irradiation (63X); b) irradiation at $350 \mathrm{~nm}$ for $30 \mathrm{~min}(63 X)$; c) irradiation at $650 \mathrm{~nm}$ for $30 \mathrm{~min}(40 X)$; d) irradiation at $650 \mathrm{~nm}$ for $30 \mathrm{~min}$, 3D-image (40X).

\section{CONCLUSIONS}

We have developed a new chemisorption approach by which nanostructured gold surfaces endowed with broadband plasmon absorption can be efficiently functionalized with photocaged molecules. Laser-induced surface plasmon-enhanced cleavage of a photolabile protecting group efficiently generated free thiols, which underwent spontaneous covalent attachment of the uncaged entity through sulfur-gold bond formation. This could be demonstrated by conjugation of an $N$-thioethylated 1,8-naphthalimide fluorophore, originally protected by a 6-nitroveratryl group. Irradiation of the caged fluorophore at the surfaces, at a longer wavelength otherwise inefficient for deprotection, resulted in fluorescently-labeled gold-nanoisland surfaces. This represents the first demonstration of using plasmon-enhanced two-photon excitation for covalent conjugation at plasmonic hotspots. These results not only point to the possibility of achieving ultrasensitive sensor devices, but also promote further development of plasmonic nanostructure functionalization with various biomolecules, leading to a variety of applications in the biomedical field.

\section{EXPERIMENTAL}

\section{General}

Piperidine was from Alfa Aesar, anhydrous lithium hydroxide was from Lancaster, and cysteamine hydrochloride, 4,5-dimethoxy-2-nitrobenzyl bromide, and 4-bromo-1,8-naphthalic anhydride were from Sigma Aldrich. HPLC-grade ethanol, methanol, dichloromethane, ethyl acetate, and hexane were used throughout. Water used was from a deionization water purification system. Gold-nanoisland-featured, three-layer plasmonic nanostructures were prepared as previously reported, ${ }^{[57]}$ composed of a gold nanoparticle layer on top of a thin layer of $\mathrm{Al}_{2} \mathrm{O}_{3}$, and a reflecting layer of gold, mounted on a silicon substrate. Flat, featureless, 
gold-plated quartz crystals were from Attana AB. NMR data were recorded on a Bruker DMX 500 spectrometer at $500 \mathrm{MHz}\left({ }^{1} \mathrm{H}\right)$ and $126 \mathrm{MHz}\left({ }^{13} \mathrm{C}\right)$. Chemical shifts $(\delta)$ are reported in parts per million (ppm) values with residual $\mathrm{CHCl}_{3}\left({ }^{1} \mathrm{H}: \delta=7.26\right)$ or $\mathrm{CDCl}_{3}\left({ }^{13} \mathrm{C}=77.16\right)$ as internal references. $J$-values are given in hertz $(\mathrm{Hz})$. Melting points (uncorrected) were recorded using a Stuart SMP10 melting point apparatus. Thin layer chromatography (TLC) was performed on precoated Cromatofolios AL Silica gel 60 F254 plates (Merck). ESI-MS spectra were recorded in positive mode on a Finnigan LCQ Advantage Max: LC-MS/MS spectrometer (Thermo Fisher Science) with sample analysis through standard ESI+ acquisition parameters. UV-Vis absorption spectra were collected on a Varian Cary 300 Bio UV/Vis spectrophotometer. Emission spectra were recorded on a Varian Cary Eclipse fluorescence spectrophotometer. Irradiation was performed with a photochemical reactor from Rayonet Srinivasan-Griffin emitting at $350 \mathrm{~nm}$ or a $650 \mathrm{~nm}$ laser pointer with an intensity of 2 $\mathrm{mW} \cdot \mathrm{cm}^{-2}$. Confocal imaging was carried out using a Zeiss Laser Scanning Microscope 510 Zuidhorst 178 equipped with Zen software and 10x and 63x air objectives. FT-IR spectra were obtained using a PerkinElmer IR-spectrometer SPECTRUM 2000 in the ATR mode.

\section{Synthesis}

2-((4,5-Dimethoxy-2-nitrobenzyl)thio)ethan-1-amine (Compound 2). ${ }^{[66]} \mathrm{LiOH}(17 \mathrm{mg}$, $0.72 \mathrm{mmol})$ was dissolved in water $(1 \mathrm{~mL})$ and ethanol $(3 \mathrm{~mL})$ was added. The resulting solution was added to cysteamine hydrochloride $(41 \mathrm{mg}, 0.36 \mathrm{mmol})$ followed by dropwise addition of 6-nitroveratryl bromide (1) $(100 \mathrm{mg}, 0.36 \mathrm{mmol})$ under stirring. The reaction mixture was stirred for $40 \mathrm{~min}$ at $40{ }^{\circ} \mathrm{C}$, after which ethanol was removed in vacuo. Water $(5 \mathrm{~mL})$ was subsequently added and the mixture was extracted with dichloromethane $(3 \times 10 \mathrm{~mL})$, dried over anhydrous $\mathrm{Na}_{2} \mathrm{SO}_{4}$, concentrated in vacuo, and purified by flash column chromatography over silica gel $(60 \AA, 0.040-0.063 \mathrm{~mm}$ (SDS) using a mobile phase consisting of a mixture of dichloromethane-methanol (gradient from $2 \% \mathrm{v} / \mathrm{v}$ methanol/dichloromethane to $10 \% \mathrm{v} / \mathrm{v}$ methanol/dichloromethane) to afford pure compound 2 (93 mg, 94\%). ${ }^{1} \mathrm{H}$ NMR (500 MHz, $\mathrm{CDCl}_{3}$ ): $\delta_{\mathrm{ppm}} 7.59$ (s, 1H, Ar- $H$ ), 6.93 (s, 1H, Ar- $\left.H\right), 4.10$ (s, 2H, Ar- $\left.\mathrm{CH}_{2}\right), 3.96$ (s, 3H, O-CH $\mathrm{CH}_{3}, 3.92$ (s, 3H, O-CH3), 2.91 (brs, 2H, N-CH2), 2.64 (t, $\left.2 \mathrm{H}, J=6.5 \mathrm{~Hz}, \mathrm{~S}-\mathrm{CH}_{2}\right) .{ }^{13} \mathrm{C} \mathrm{NMR}\left(126 \mathrm{MHz}, \mathrm{CDCl}_{3}\right): \delta_{\mathrm{ppm}} 153.0,147.9,140.9,129.0$, 113.2, 108.5, 56.5, 56.4, 41.1, 36.4, 33.6. mp: $91-93{ }^{\circ} \mathrm{C}$. ESI-MS (positive mode): Calcd for $\mathrm{C}_{11} \mathrm{H}_{16} \mathrm{~N}_{2} \mathrm{O}_{4} \mathrm{~S}:[\mathrm{M}+\mathrm{H}]^{+} \mathrm{m} / \mathrm{z}=273.0909$. Found: $[\mathrm{M}+\mathrm{H}]^{+} \mathrm{m} / \mathrm{z}=273.0667$. FT-IR (ATR, neat): See Supporting Information.

6-Bromo-2-(2-((4,5-dimethoxy-2-nitrobenzyl)thio)ethyl)-1H-benzo[de]isoquinoline-

1,3(2H)-dione (Compound 4). A mixture of 6-bromo-1H,3H-benzo[de]isochromene-1,3dione (3) (95 $\mathrm{mg}, 0.34 \mathrm{mmol})$ and compound $2(93 \mathrm{mg}, 0.34 \mathrm{mmol})$ in ethanol $(5 \mathrm{~mL})$ was heated under reflux for $4 \mathrm{~h}$, and then cooled down to room temperature followed by storage in a freezer overnight. After isolation by filtration and drying, compound 4 was obtained as a white powder (145 mg, 80\%). ${ }^{1} \mathrm{H}$ NMR $\left(500 \mathrm{MHz}, \mathrm{CDCl}_{3}\right): \delta_{\mathrm{ppm}} 8.62(\mathrm{~d}, 1 \mathrm{H}, J=7.5 \mathrm{~Hz}$, Naph-H), 8.60 (d, 1H, $J=8.0$ Hz, Naph-H), 8.38 (d, $1 \mathrm{H}, J=8.0 \mathrm{~Hz}, \mathrm{Naph}-H), 8.06$ (d, 1H, $J=7.5 \mathrm{~Hz}$, Naph-H), 7.86 (t, $1 \mathrm{H}, J=8.0 \mathrm{~Hz}$, Naph-H), 7.64 (s, $1 \mathrm{H}$, Ar- $H$ ), 7.12 (s, $1 \mathrm{H}$, Ar- $H$ ), 4.39 (t, $\left.2 \mathrm{H}, J=7.6 \mathrm{~Hz}, \mathrm{~N}-\mathrm{CH}_{2}\right), 4.24\left(\mathrm{~s}, 2 \mathrm{H}, \mathrm{Ar}-\mathrm{CH}_{2}\right), 4.07\left(\mathrm{~s}, 3 \mathrm{H}, \mathrm{O}-\mathrm{CH}_{3}\right), 3.91(\mathrm{~s}, 3 \mathrm{H}$, $\left.\mathrm{O}-\mathrm{CH}_{3}\right), 2.80\left(\mathrm{t}, 2 \mathrm{H}, J=7.6 \mathrm{~Hz}, \mathrm{~S}-\mathrm{CH}_{2}\right) .{ }^{13} \mathrm{C} \mathrm{NMR}\left(126 \mathrm{MHz}, \mathrm{CDCl}_{3}\right): \delta_{\mathrm{ppm}} 163.5,163.5$, $152.9,147.8,140.3,133.6,132.1,131.3,131.2$, 130.7, 130.6, 129.6, 129.1, 128.2, 122.9, 122.0, 113.9, 108.9, 56.6, 56.4, 39.8, 34.0, 28.9. mp: 206-208 ${ }^{\circ} \mathrm{C}$. ESI-MS (positive mode): Calcd for $\mathrm{C}_{23} \mathrm{H}_{19} \mathrm{BrN}_{2} \mathrm{O}_{6} \mathrm{~S}$ : $[\mathrm{M}+\mathrm{Na}]^{+} \mathrm{m} / \mathrm{z}=553.0045$. Found: $[\mathrm{M}+\mathrm{Na}]^{+} \mathrm{m} / \mathrm{z}=553.1333$. FTIR (ATR, neat): See Supporting Information. 


\section{2-(2-((4,5-Dimethoxy-2-nitrobenzyl)thio)ethyl)-6-(piperidin-1-yl)-1 H-}

benzo[de]isoquinoline-1,3(2H)-dione (NV-SNaph). ${ }^{[67]}$ Compound 4 (50 mg, $0.094 \mathrm{mmol}$ ) was heated to reflux in piperidine $(2.5 \mathrm{~mL})$ overnight under a nitrogen stream. The solvent was removed in vacuo and the resulting residue purified by flash column chromatography over silica gel $(60 \AA, 0.040-0.063 \mathrm{~mm}$ (SDS) using a mobile phase consisting of a mixture of hexane-ethyl acetate (gradient from $30 \% \mathrm{v} / \mathrm{v}$ ethyl acetate/hexane to $100 \% \mathrm{v} / \mathrm{v}$ acetate/hexane) to give NV-SNaph as a yellow solid (26 mg, 50\%). ${ }^{1} \mathrm{H}$ NMR $(500 \mathrm{MHz}$, $\left.\mathrm{CDCl}_{3}\right): \delta_{\mathrm{ppm}} 8.54(\mathrm{~d}, 1 \mathrm{H}, J=7.5 \mathrm{~Hz}, \mathrm{Naph}-H), 8.47-8.43(\mathrm{~m}, 2 \mathrm{H}, \mathrm{Naph}-H), 7.70(\mathrm{~d}, 1 \mathrm{H}$, $J=7.5 \mathrm{~Hz}$, Naph-H), 7.68 (s, $1 \mathrm{H}, \operatorname{Ar}-H), 7.20$ (d, $1 \mathrm{H}, J=8.0 \mathrm{~Hz}, \mathrm{Naph}-H), 7.18$ (s, 1H, Ar- $H$ ), 4.40 (t, 2H, J=7.5 Hz, N-CH $H_{2}, 4.25$ (s, 2H, Ar-CH $\left.H_{2}\right), 4.08$ (s, 3H, O-CH $H_{3}, 3.92$ (s, $3 \mathrm{H}, \mathrm{O}-\mathrm{CH}_{3}$ ), 3.26 (brs, 4H, 2xN $\mathrm{pip}-\mathrm{CH}_{2}$ ), 2.76 (t, $2 \mathrm{H}, J=7.5 \mathrm{~Hz}, \mathrm{~S}-\mathrm{CH}_{2}$ ), 1.92 (brs, 4H, $2 \mathrm{xN}_{\text {pip }} \mathrm{CH}_{2}-\mathrm{CH}_{2}$ ), 1.74 (brs, $2 \mathrm{H}, \mathrm{N}_{\text {pip }} \mathrm{CH}_{2} \mathrm{CH}_{2}-\mathrm{CH}_{2}$ ). ${ }^{13} \mathrm{C} \mathrm{NMR}\left(126 \mathrm{MHz}, \mathrm{CDCl}_{3}\right)$ : $\delta_{\text {ppm }} 164.4,163.9,152.9,147.8,140.2,132.6,131.2,130.9,130.0,129.9,126.2,125.6,122.9$, $115.0,114.1,109.0,56.6,56.4,54.7,39.5,33.8,29.7,28.7,26.0,24.2 . \mathrm{mp}: 160-162{ }^{\circ} \mathrm{C}$. ESIMS (positive mode): Calcd for $\mathrm{C}_{28} \mathrm{H}_{29} \mathrm{~N}_{3} \mathrm{O}_{6} \mathrm{~S}:[\mathrm{M}+\mathrm{Na}]^{+} \mathrm{m} / \mathrm{z}=558.1669$. Found: $[\mathrm{M}+\mathrm{Na}]^{+}$ $\mathrm{m} / \mathrm{z}=558.4000$. FT-IR (ATR, neat): See Supporting Information.

\section{NV-SNaph photolysis}

NMR: A solution of $\mathbf{N V}$-SNaph in $\mathrm{CDCl}_{3}(10 \mathrm{mg} / \mathrm{mL})$ in an NMR tube was placed inside a photochemical reactor and irradiated at $350 \mathrm{~nm}$ with an intensity of $1.8-2.0 \mathrm{mWcm}^{-2}$. At specific time intervals, ${ }^{1} \mathrm{H}-\mathrm{NMR}$ spectra were recorded at room temperature. UV-Vis: A solution of NV-SNaph in chloroform $\left(10^{-5} \mathrm{M}\right)$ in a quartz cuvette was irradiated at $350 \mathrm{~nm}$ in a photochemical reactor at an intensity of $2.8-3.2 \mathrm{mWcm}^{-2}$ for 1 hour. Absorption spectra were collected at specific irradiation times at a wavelength range from 225 to $600 \mathrm{~nm}$.

\section{Photoinduced surface functionalization}

A solution of NV-SNaph in dichloromethane $(10 \mathrm{mg} / \mathrm{mL})$ was dropped onto the gold-plated quartz crystal surfaces $(50 \mu \mathrm{L})$ and gold-nanoisland substrates $(100 \mu \mathrm{L})$, after which the surfaces were dried under vacuum overnight. The non-irradiated control samples were subsequently washed with dichloromethane several times and then soaked in dichloromethane overnight to remove all physisorbed NVB-SNaph on the surfaces. The remaining samples were first irradiated at 350 or $650 \mathrm{~nm}\left(\mathrm{I}=2 \mathrm{mWcm}^{-2}\right)$ for $30 \mathrm{~min}$, and subsequently left under an $\mathrm{N}_{2}$ flow for several hours, followed by washing with dichloromethane in the same way as with the control samples. All samples were finally dried under vacuum overnight before the CLSM experiments.

\section{AUTHOR INFORMATION}

\section{Corresponding Author}

Olof Ramström; E-mail: olof ramstrom@uml.edu

\section{ACKNOWLEDGEMENTS}

This study was in part supported by the Swedish Research Council and the People Programme (Marie Curie Actions) of the European Union's Seventh Framework Programme FP7 under REA grant agreement no 264645. 


\section{REFERENCES}

[1] M.-H. Seo, J.-Y. Yoo, M.-S. Jo, J.-B. Yoon, Adv. Mater. 2020, 32, 1907082.

[2] Y.-P. Xie, Y.-L. Shen, G.-X. Duan, J. Han, L.-P. Zhang, X. Lu, Mater. Chem. Front. 2020, 4, 2205-2222.

[3] G. Xie, M. R. Martinez, M. Olszewski, S. S. Sheiko, K. Matyjaszewski, Biomacromolecules 2019, 20, $27-54$. [4] N. Panwar, A. M. Soehartono, K. K. Chan, S. Zeng, G. Xu, J. Qu, P. Coquet, K.-T. Yong, X. Chen, Chem. Rev. 2019, 119, 9559-9656.

[5] J. Leng, Z. Wang, J. Wang, H.-H. Wu, G. Yan, X. Li, H. Guo, Y. Liu, Q. Zhang, Z. Guo, Chem. Soc. Rev. 2019, 48, 3015-3072.

[6] Z. Xi, H. Ye, X. Xia, Chem. Mater. 2018, 30, 8391-8414.

[7] M. Qiu, W. X. Ren, T. Jeong, M. Won, G. Y. Park, D. K. Sang, L.-P. Liu, H. Zhang, J. S. Kim, Chem. Soc. Rev. 2018, 47, 5588-5601.

[8] L. Liu, Y. Zhou, S. Liu, M. Xu, ChemElectroChem 2018, 5, 6-19.

[9] H. Lin, Y. Chen, J. Shi, Chem. Soc. Rev. 2018, 47, 1938-1958.

[10] C. Cheng, S. Li, A. Thomas, N. A. Kotov, R. Haag, Chem. Rev. 2017, 117, 1826-1914.

[11] S. Mao, J. Chang, H. Pu, G. Lu, Q. He, H. Zhang, J. Chen, Chem. Soc. Rev. 2017, 46, 6872-6904.

[12] G. Wen, Z. Guo, W. Liu, Nanoscale 2017, 9, 3338-3366.

[13] R. Gordon, Nanotechnology 2019, 30, 212001.

[14] L. Wang, Q. Li, Chem. Soc. Rev. 2018, 47, 1044-1097.

[15] X. Li, S. Lee, J. Yoon, Chem. Soc. Rev. 2018, 47, 1174-1188.

[16] D. G. Baranov, M. Wersäll, J. Cuadra, T. J. Antosiewicz, T. Shegai, ACS Photonics 2018, 5, 24-42.

[17] P. Vasa, C. Lienau, ACS Photonics 2018, 5, 2-23.

[18] S. Kundu, A. Patra, Chem. Rev. 2017, 117, 712-757.

[19] S. Yu, X. Wu, Y. Wang, X. Guo, L. Tong, Adv. Mater. 2017, 29, 1606128.

[20] Y. Zang, J. Lei, H. Ju, Biosens. Bioelectron. 2017, 96, 8-16.

[21] A. Kristensen, J. K. W. Yang, S. I. Bozhevolnyi, S. Link, P. Nordlander, N. J. Halas, N. A. Mortensen, Nat. Rev. Mater. 2016, 2, 16088.

[22] X. Wang, S.-C. Huang, S. Hu, S. Yan, B. Ren, Nat. Rev. Phys. 2020, 2, 253-271.

[23] P. Zhang, D. Wang T., J. Gong, Adv. Mater. 2015, 27, 5328-5342.

[24] P. N. Abadian, C. P. Kelley, E. D. Goluch, Anal. Chem. 2014, 86, 2799-2812.

[25] M. R. Gonçalves, J. Phys. D: Appl. Phys. 2014, 47, 213001.

[26] E. C. A. Stigter, G. J. de Jong, W. P. van Bennekom, Trends Anal. Chem. 2013, 45, 107-120.

[27] C. M. Galloway, M. P. Kreuzer, S. S. Aćimović, G. Volpe, M. Correia, S. B. Petersen, M. T. Neves-Petersen, R. Quidant, Nano Lett. 2013, 13, 4299-304.

[28] J. Cunha, T.-L. Guo, G. Della Valle, A. N. Koya, R. Proietti Zaccaria, A. Alabastri, Adv. Opt. Mater. 2020, $8,2001225$.

[29] H. Song, H. Ahn, T. Kim, Y. Lee, J.-R. Choi, K. Kim, Appl. Spectrosc. Rev. 2019, 54, 482-508.

[30] C. Bradac, Adv. Opt. Mater. 2018, 6, 1800005.

[31] H. Wei, H. Xu, Mater Today 2014, 17, 372-380.

[32] O. M. Maragò, P. H. Jones, P. G. Gucciardi, G. Volpe, A. C. Ferrari, Nat. Nanotechnology 2013, 8, 807-819.

[33] M. Achermann, J. Phys. Chem. Lett. 2010, 1, 2837-2843.

[34] A. Poletti, G. Fracasso, G. Conti, R. Pilot, V. Amendola, Nanoscale 2015, 7, 13702-14.

[35] L. K. Chin, T. Son, J.-S. Hong, A.-Q. Liu, J. Skog, C. M. Castro, R. Weissleder, H. Lee, H. Im, ACS Nano 2020, 14, 14528-14548.

[36] V. T. Tran, H.-Q. Nguyen, Y.-M. Kim, G. Ok, J. Lee, Nanomaterials 2020, 10, 1-19.

[37] Y. Mantri, J. V. Jokerst, ACS Nano 2020, 14, 9408-9422.

[38] V. De Matteis, L. Rizzello, M. Cascione, E. Liatsi-Douvitsa, A. Apriceno, R. Rinaldi, Nanomaterials 2020, $10,1083$. 
[39] C. Li, Y. Jin, Adv. Funct. Mater. 2020, 2008031.

[40] Z. Li, L. Leustean, F. Inci, M. Zheng, U. Demirci, S. Wang, Biotechnol. Adv. 2019, 37, 107440.

[41] M. Sharifi, F. Attar, A. A. Saboury, K. Akhtari, N. Hooshmand, A. Hasan, M. A. El-Sayed, M. Falahati, J. Controlled Release 2019, 311-312, 170-189.

[42] F. Hong, R. Blaikie, Adv. Opt. Mater. 2019, 7, 1801653.

[43] J. D. Spitzberg, A. Zrehen, X. F. van Kooten, A. Meller, Adv. Mater. 2019, 31, 1900422.

[44] A. Prasad, J. Choi, Z. Jia, S. Park, M. R. Gartia, Biosens. Bioelectron. 2019, 130, 185-203.

[45] X. Ma, S. J. Sim, J. Mater. Chem. B 2020, 8, 6197-6216.

[46] H. Zong, X. Mu, M. Sun, Appl. Mater. Today 2019, 15, 43-57.

[47] W. Park, D. Lu, S. Ahn, Chem. Soc. Rev. 2015, 44, 2940-2962.

[48] J. Zhou, Q. Liu, W. Feng, Y. Sun, F. Li, Chem Rev 2015, 115, 395-465.

[49] R.-Y. He, Y.-D. Su, K.-C. Cho, C.-Y. Lin, N.-S. Chang, C.-H. Chang, S.-J. Chen, Opt. Express 2009, 17, 5987.

[50] D.-S. Wang, F.-Y. Hsu, C.-W. Lin, Opt. Express 2009, 17, 11350.

[51] H. M. Kim, B. R. Cho, Chem. Rev. 2015, 115, 5014-5055.

[52] J. H. Lin, C.-Y. Tseng, C.-T. Lee, H.-C. Kan, C. C. Hsu, Opt. Express 2013, 21, 24318-25.

[53] G. V. Hartland, L. V. Besteiro, P. Johns, A. O. Govorov, ACS Energy Lett. 2017, 2, 1641-1653.

[54] A. J. Wilson, K. A. Willets, Annu. Rev. Anal. Chem. 2016, 9, 27-43.

[55] J.-C. Tinguely, I. Sow, C. Leiner, J. Grand, A. Hohenau, N. Felidj, J. Aubard, J. R. Krenn, Bionanoscience 2011, $1,128-135$.

[56] P. Tiwari, K. Vig, V. Dennis, S. Singh, Nanomaterials 2011, 1, 31-63.

[57] M. Yan, J. Dai, M. Qiu, J. Opt. 2014, 16, 025002.

[58] R. M. Duke, E. B. Veale, F. M. Pfeffer, P. E. Kruger, T. Gunnlaugsson, Chem. Soc. Rev. 2010, $39,3936$.

[59] Y. Q. Gao, R. A. Marcus, J. Phys. Chem. A 2002, 106, 1956-1960.

[60] S. Saha, A. Samanta, J. Phys. Chem. A 2002, 106, 4763-4771.

[61] A. Peters, Dye. Pigment. 1985, 6, 349-375.

[62] M. J. Hansen, W. A. Velema, M. M. Lerch, W. Szymanski, B. L. Feringa, Chem. Soc. Rev. 2015, 44, 3358-77.

[63] C. G. Bochet, Angew. Chem. Int. Ed. 2001, 40, 2071-2073.

[64] A. Patchornik, B. Amit, R. B. Woodward, J. Am. Chem. Soc. 1970, 92, 6333-6335.

[65] J. P. Casey, R. A. Blidner, W. T. Monroe, Mol. Pharm. 2009, 6, 669-685.

[66] S. Ghosh, G. P. Tochtrop, Tetrahedron Lett. 2009, 50, 1723-1726.

[67] C. J. McAdam, J. L. Morgan, B. H. Robinson, J. Simpson, P. H. Rieger, A. L. Rieger, Organometallics 2003, 22, 5126-5136.

[68] A. Blanc, C. G. Bochet, J. Org. Chem. 2002, 67, 5567-5577. 